\title{
Some experimental and modeling results of widely varying urban environments on train mobile radio communication
}

\author{
M. V. S. N. Prasad ${ }^{1, *, \dagger}$, Rajendra Singh ${ }^{2}$, S. K. Sarkar ${ }^{1}$ and A. D. Sarma ${ }^{3}$ \\ ${ }^{1}$ Radio and Atmospheric Sciences Division, National Physical Laboratory, Dr. K. S. Krishnan Road, \\ New Delhi-110012, India \\ ${ }^{2}$ Telecom Regulatory Authority of India, A2/14, Safdarjang Enclave, New Delhi-110029, India \\ ${ }^{3}$ Navigational Electronics Research and Training Unit, College of Engineering, Osmania University, \\ Hyderabad-500007, India
}

\section{Summary}

A comparative study of urban mobile radio wave propagation characteristics in the UHF band has been carried out based on the field strength measurements conducted inside a moving train in two widely varying urban environments. Various prediction techniques are employed to compare the observed path losses with those of predicted ones in both the environments. The major fall out of the present study is the modification of Xia's model, which gave better agreement with the observed results. The deviations of the prediction techniques and their suitability have been discussed. Copyright (C) 2006 John Wiley \& Sons, Ltd.

KEY WORDS: urban environment; path losses; train measurements; models

\section{Introduction}

Land mobile propagation measurements in the VHF/ UHF band and their comparison with empirical models, theoretical models and ray tracing techniques have been carried out by a good number of workers. But not many mobile train radio measurements are reported in the literature. The terrestrial cellular systems were developed based on the measurements conducted from vehicles on the road. The short-term fading, long-term fading, path loss and other characterization deduced from road based vehicles may not be directly applicable to train based conditions, changing from urban to suburban, to open. These changes can drastically influence the system characteristics.
Optimum prediction of path loss helps to improve the coverage area of a base station and also helps to minimize the interference problems. The accuracy of different prediction methods were improved by various workers especially in urban environments, where most of the mobile measurements were conducted [1-3]. Comparison of different prediction models with observed results is very important in urban environment rather than in suburban or open due to the complexity of propagation mechanisms. Goncalves developed a mathematical expression that takes into account the crossroad's influence on the average received power [4]. The model incorporates an extra term that accounts for decrease in the propagation loss due to crossroad's influence.

*Correspondence to: M. V. S. N. Prasad, Radio and Atmospheric Sciences Division, National Physical Laboratory, Dr. K. S. Krishnan Road, New Delhi-110012, India.

†E-mail: mvprasad@mail.nplindia.ernet.in

Copyright (C) 2006 John Wiley \& Sons, Ltd. 
McGuire et al. demonstrated the utility of path loss survey measurements for estimating the position of mobile terminals[5].

\section{Experimental and Environmental Details}

In order to understand these implications, an attempt is made to compare the mobile train radio measurements conducted in the UHF band at $320 \mathrm{MHz}$ in two densely crowded cities viz: New Delhi base station and Kurla base station in Bombay (now known as Mumbai). Though both the cities can be classified as dense urban, the topographical and building structures of the cities are totally different. New Delhi is characterized by broad roads with reasonably high rise buildings and some good amount of greenery in between. The city is spread in all the four directions. Bombay is much more densely populated than New Delhi and the whole city takes the shape of a narrow rectangle due to its proximity to Arabian sea on the western side. The street widths are narrow in Bombay compared with New Delhi and the buildings are much taller with 15-20 storeys at some places. Due to these large differences in their topography and varying degrees of urbanization, mobile radio propagation characteristics in these widely varying environments would be totally different. Maps of New Delhi and Kurla base stations are presented in Figures 1 and 2 .

In order to investigate the effect of varying degrees of urbanization on UHF mobile train radio propagation, field strength measurements were conducted utilizing the track side microwave towers as base stations. These measurements are narrow band ones and the receiving antenna is located outside the moving train. It is a low profile omni-directional antenna located on the roof of the coach. Hence, the shielding effects of the train's carriage need not be considered. The height of the mobile antenna is $3 \mathrm{~m}$ in both cases while that of New Delhi base station antenna is $40 \mathrm{~m}$ above ground level. The e.r.p's of New Delhi base station is $+37 \mathrm{dBm}$ while that of Kurla is $+39.5 \mathrm{dBm}$. The antennas are vertically polarized. The urban environment prevailed up to a distances of $12 \mathrm{~km}$ on either side of Kurla base station.

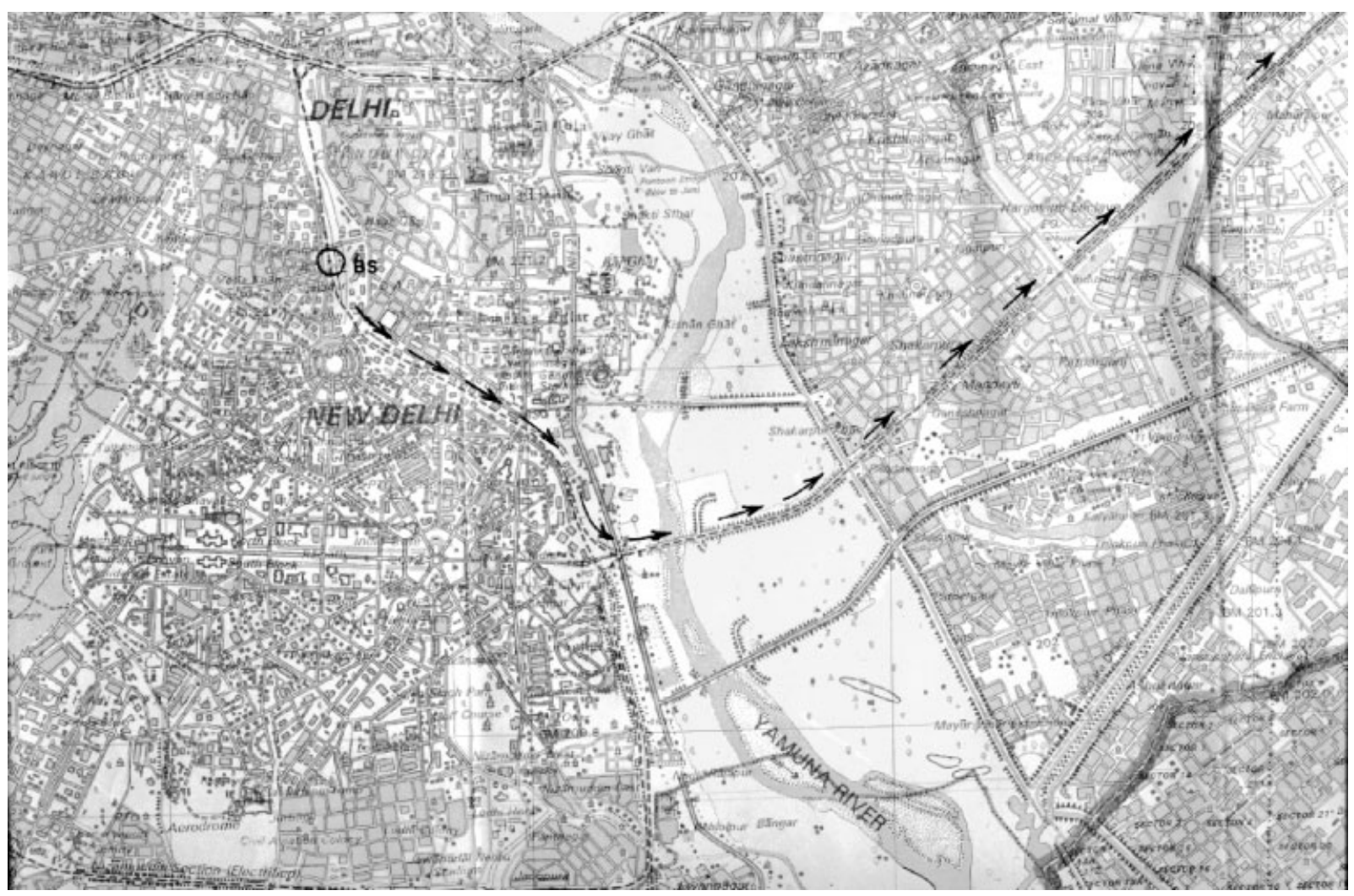

Fig. 1. Map of New Delhi base station area. 


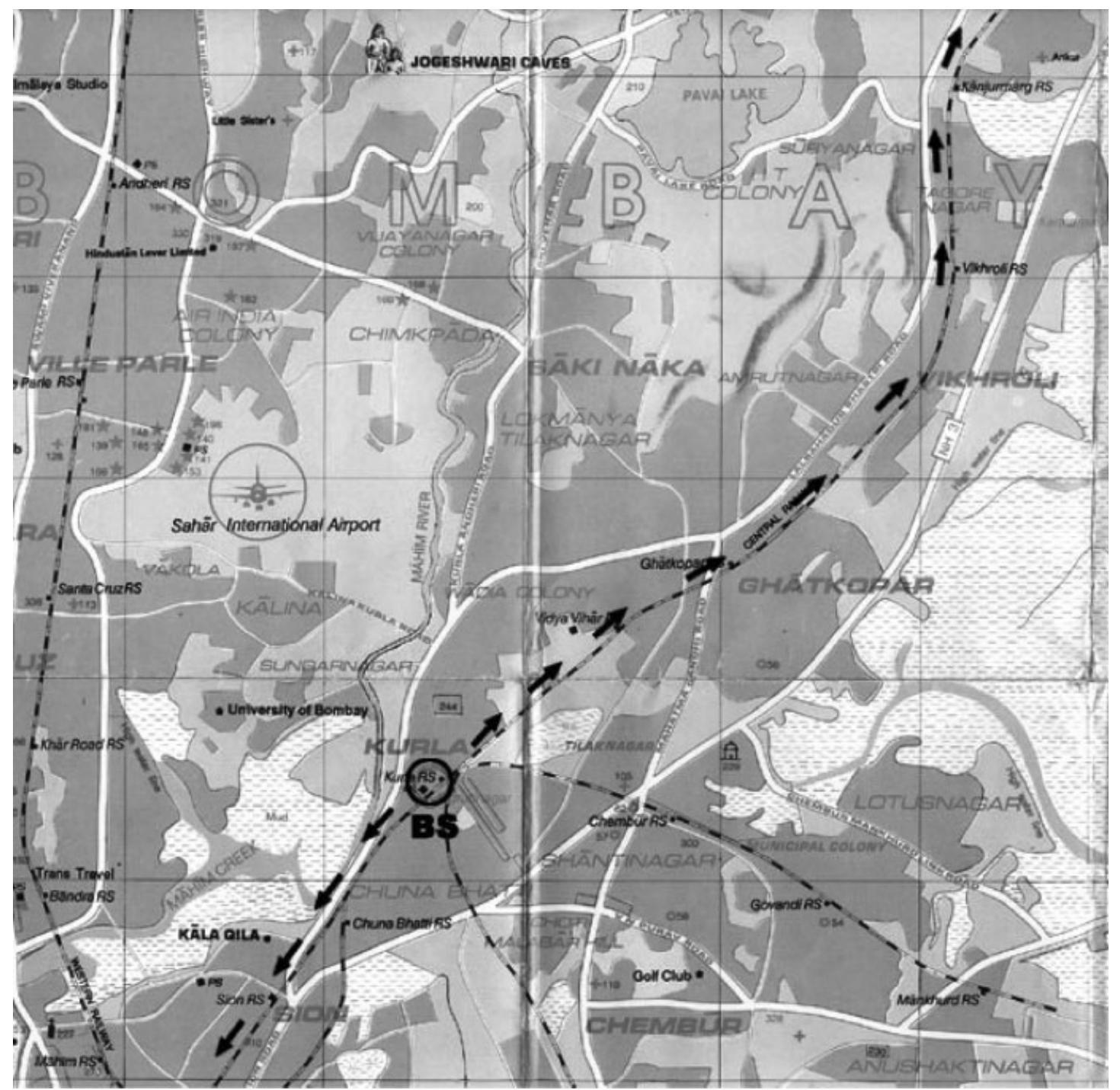

Fig. 2. Map of Kurla base station area.

In the case of New Delhi base station urban environment prevailed up to $6 \mathrm{~km}$.

The recorded carrier levels were averaged over $100 \mathrm{~m}$. The receiver sensitivity shall be better than $0.5 \mu \mathrm{V}$ for $20 \mathrm{~dB}$ signal to noise ratio measured at $\mathrm{RF}$ signal modulated with $1000 \mathrm{~Hz}$ at $60 \%$ of the peak deviations into the duplexer antenna input. The dynamic adjacent channel selectivity shall be $70 \mathrm{~dB}$ or better.

\section{Results}

The signal strength values are converted into path loss values and compared with path losses predicted from

Copyright (C) 2006 John Wiley \& Sons, Ltd. various methods like (1) Hata [6], (2) Blomquist and Ladell [7], (3) Walfich and Bertoni [8], (4) Egli [9], (5) Ibrahim and Parsons [10] and (6) uniform theory of diffraction [11]. Figure 3 depicts the comparison of various prediction methods with the observed path losses of New Delhi base station. The base station is located at a distance marked zero and the positive distances on the left side correspond to the measurements of New Delhi base station when the train was moving towards next base station. The distance$2 \mathrm{~km}$ corresponds to the measurement of the New Delhi base station on the opposite side of the base station. The observed path loss increases, up to $6 \mathrm{~km}$ rapidly by $26 \mathrm{~dB}$ and after $6 \mathrm{~km}$ shows a decreasing trend. At this distance the path loss decreases by $6 \mathrm{~dB}$. 


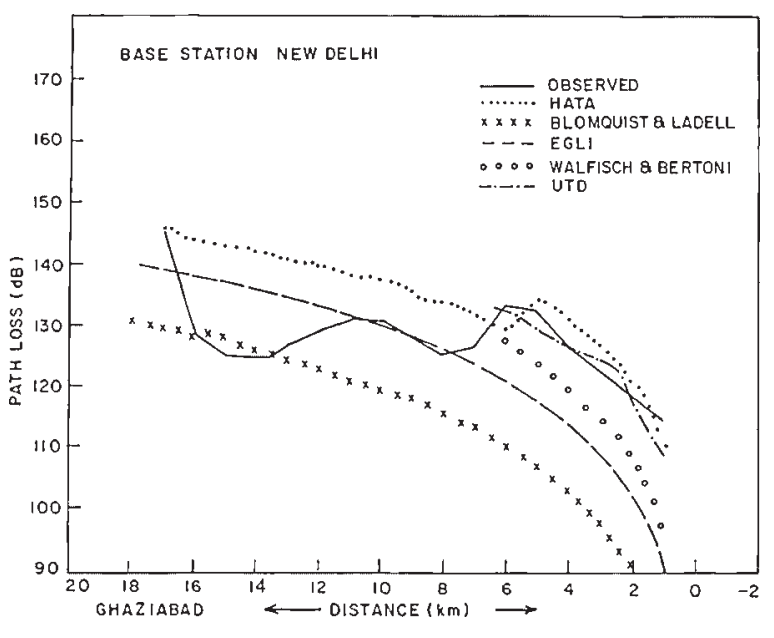

Fig. 3. Comparison of observed path losses of New Delhi base station with various prediction methods.

This corresponds to the change in environmental conditions from urban to suburban conditions. From New Delhi base station up to a distance of $6 \mathrm{~km}$, multi-storey buildings and densely populated areas are seen along the track. The large values of the path loss could be due to the multiple reflections and diffraction of the signal from the buildings. After $6 \mathrm{~km}$, suburban conditions were prevailing. In Hata's prediction method from $6 \mathrm{~km}$ onwards, we have introduced correction factors for suburban environment. Up to $6 \mathrm{~km}$, Hata's equation for urban environment has been used. Hata's curve follows the observed path losses very closely in the urban zone with a deviation of around $3 \mathrm{~dB}$ initially, and at $10 \mathrm{~km}$ distance the deviation increases to $8 \mathrm{~dB}$. The deviation is slightly higher in the suburban zone. It seems, the deviations of Blomquist \& Ladell's methods are more in the urban region and less in the suburban region. The reason could be due to the fact that these two methods have no correction factors for urban environment. Both the methods have underestimated the path losses. Walfisch \& Bertoni's method [8] describes the influence of residential, commercial and light industrial buildings that constitute the urban land area. The model is applicable up to a distance of $6 \mathrm{~km}$ in the present case where the urban conditions have changed into suburban conditions. In the urban region, the model underestimates the path loss by $5 \mathrm{~dB}$. The calculations of path loss due to Ibrahim \& Parsons's method are not shown in Figure 3 because it gave large deviations. At $1 \mathrm{~km}$, the deviation is $20 \mathrm{~dB}$, at $4 \mathrm{~km}$ it is $16 \mathrm{~dB}$ and at $5 \mathrm{~km}$ it is $19 \mathrm{~dB}$. Here, their semi-empirical method is employed.

Copyright (C) 2006 John Wiley \& Sons, Ltd.
In the present study, uniform theory of diffraction based on Zhang's approach has been utilized to calculate the path loss. It consists of path loss due to free space, due to local row of buildings closing the mobile and due to multiple diffractions. Here rows of buildings have been modeled as rows of knife-edges or half screen with an equal spacing. Authors had some information on the height of buildings and street widths in the urban region along the track. This was utilized to calculate the multiple diffraction losses. The path losses deduced from UTD for vertical polarization are also shown in Figure 3. These are in reasonable agreement with the observed values. At $1 \mathrm{~km}$, the deviation is $5 \mathrm{~dB}$, at $3 \mathrm{~km}$ it is around $2 \mathrm{~dB}$ and at $6 \mathrm{~km}$ it is $1 \mathrm{~dB}$. It is seen from calculations that at small values of $d_{r}$, the contribution of diffracted electric field is larger. The computations also showed that the path loss for horizontal polarization is greater than the vertical polarization by $10 \mathrm{~dB}$. In the present case only vertical polarization is used. In case of the New Delhi base station, the path loss exponent is found to vary between 0.5 and 2.2 with the maximum value occurring at $5.5 \mathrm{~km}$ distance.

Figure 4 shows the comparison of path losses deduced from the observations of Kurla base station with the same prediction methods. The Kurla base station is situated at a distance marked zero and the observed path losses plotted on the left side correspond to that of measurements conducted when the train was moving towards Kalyan side (the base station whose measurements are not discussed here). The observed path losses plotted on the right side correspond to that of measurements when the train was moving away from Kurla base station on the opposite side. The observed path loss increases steadily on either side and a maximum path loss of $145 \mathrm{~dB}$

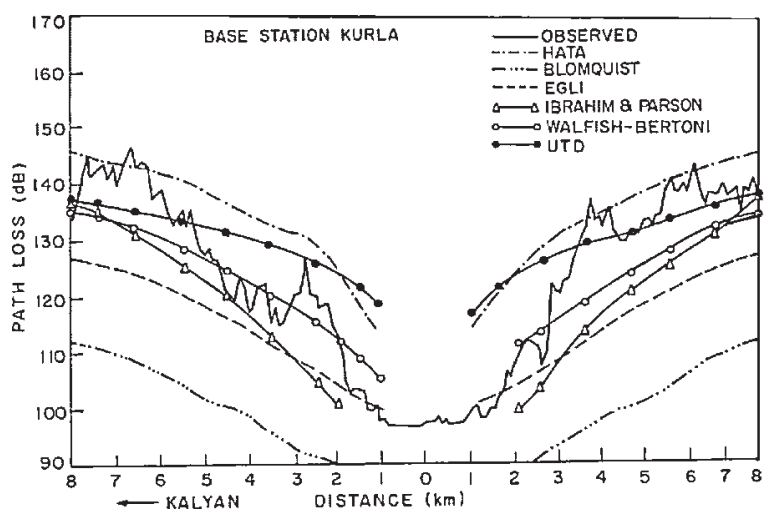

Fig. 4. Comparison of observed path losses of Kurla base station with various prediction methods.

Wirel. Commun. Mob. Comput. 2006; 6:105-112 
is seen at a distance of $6.5 \mathrm{~km}$ on Kalyan side. Hata's method overestimates the observed values till $6 \mathrm{~km}$ with a maximum deviation of $15 \mathrm{~dB}$ at $4 \mathrm{~km}$ on the Kalyan side. On the other side, the deviation is more till $4 \mathrm{~km}$. At $3 \mathrm{~km}$ distance, the deviation is $9 \mathrm{~dB}$ and at $6 \mathrm{~km}$ the deviation remains within $1 \mathrm{~dB}$. It appears that on both sides the deviation is more till $4 \mathrm{~km}$ and the deviation decreases beyond $4 \mathrm{~km}$. In the case of Ibrahim and Parsons' method on the Kalyan side, the deviation is high of the order of $12 \mathrm{~dB}$ at $3 \mathrm{~km}$ and the agreement is better between 4 and $5 \mathrm{~km}$. Beyond $5 \mathrm{~km}$, the predicted path loss does not follow the rise in observed path loss. On the other side, Ibrahim and Parsons' method underestimates the path loss by $5 \mathrm{~dB}$. On both sides of the base station, Blomquist and Ladell's method underestimates urban path loss by as much as $20-25 \mathrm{~dB}$. This method cannot be applied to predict urban radio wave propagation unless correction factors are incorporated. On both sides Egli's method gives good agreement up to $2-3 \mathrm{~km}$ and thereafter the predicted curve does not follow the steep rise in path loss. This could be probably due to line-of-sight propagation up to this distance and thereafter multiple diffractions and reflections of the diffracted field contribute substantially to the observed path loss. Walfisch and Bertoni's method gives very good agreement up to $5 \mathrm{~km}$ on the Kalyan side and thereafter the deviation increases. At $6 \mathrm{~km}$ the deviation is $13 \mathrm{~dB}$. On the other side, the agreement is moderate up to $3.5 \mathrm{~km}$ and there after it deviates by $10-15 \mathrm{~dB}$ between 4 and $8 \mathrm{~km}$ distances.

The agreement of UTD deduced path loss with observed values becomes better beyond $4 \mathrm{~km}$ onwards. If the loss due to reflection i.e. $3 \mathrm{~dB}$ is not taken into account, the agreement at distances below $4 \mathrm{~km}$ improves moderately. At $6 \mathrm{~km}$, the deviation of UTD on the right hand side is $6 \mathrm{~dB}$ whereas towards Kalyan side it is $1 \mathrm{~dB}$. The agreement of UTD depends on the precise choice of parameters $d_{r}$, height of the buildings, estimation of loss due to reflection of diffracted electric field etc. At closer distances, the agreement is not that good. Also an attempt is made to deduce the path loss exponent at different distances. This varies from 2.7 to 5.0 on Kalyan side of the base station and varies from 3.6 to 7.7 on the opposite side of the base station. The higher path loss exponent on the other side of the base station is due to the dense urban environment. A comparison of path loss exponents of New Delhi and Mumbai base stations showed that Mumbai environment exhibited much higher path loss exponent than New Delhi urban structure.

Copyright (C) 2006 John Wiley \& Sons, Ltd.

\subsection{Comparison of Observed Results with Xia's Model}

Xia [12] developed an analytical model for deducing path loss in urban and suburban environments. In this model, the total path loss is a sum of signal reduction due to free space wave front spreading, multiple diffraction past rows of buildings and building shadowing. This is applicable to cellular and personal communication system applications because frequency, base station antenna height, mobile station antenna height, building height and street width are explicitly present.

According to this model the total path loss available is the sum of

$$
L=L_{\mathrm{o}}+L_{\mathrm{rts}}+L_{\mathrm{md}}
$$

$L_{\mathrm{o}}$ is free space loss, $L_{\mathrm{rts}}$ is loss due to diffraction from rooftop down to street level, $L_{\mathrm{md}}$ is loss due to multiple forward diffraction past rows of buildings. $L_{\mathrm{rts}}$ is calculated using GTD by incorporating height of buildings, mobile station antenna, horizontal distance between mobile and diffraction edge (Xia assumed each building story has a height of $3 \mathrm{~m}$ ).

$L_{\mathrm{md}}$ has been calculated based on the studies of Xia and Bertoni [13]. Xia developed simplified expressions for base station antennas below the average rooftop level, above the rooftop level and near the average rooftop level. These are very easy, take less computation time and can be used by design engineers as a first order estimation.

Here Xia's model is utilized for computing path loss for two urban environments i.e. Kurla (Mumbai) and Delhi base stations, and the results are compared with the observed path losses. The path losses computed from Xia's model are 109.43, 132.30 and $143.47 \mathrm{~dB}$ at distances of 1,4 and $8 \mathrm{~km}$ respectively in the case of Kurla base station. Since these values are much higher than the observed values, attempt is made to deduce the contribution of $L_{\mathrm{rts}}$ to the path loss by modified Ikegami method $[14,15]$. Here the contribution of $L_{\mathrm{md}}$ from Xia's model is utilized and $L_{\mathrm{rts}}$ is calculated from modified Ikegami's method. These two contributions are added to free space loss to get the total path loss.

Here $L_{\mathrm{rts}}$ is computed as follows. According to COST 231, Walfisch Ikegami (WI) model $L_{\mathrm{rts}}$ is given by

$$
\begin{aligned}
L_{\mathrm{rts}}= & -16.9-10 \log w+10 \log f \\
& +20 \log \Delta h_{\text {mobile }}+L_{\text {ori }}
\end{aligned}
$$


Where, $w$ is street width, $f$ is frequency and $\Delta h_{\text {mobile }}$ is the difference between the last building height and receiver height. $L_{\text {ori }}$ is street orientation factor. For simplicity in the present study, we assumed that the propagation is in a perpendicular direction so that $L_{\text {ori }}=10 \log \sin \phi$ becomes zero [14].

Har et al. [15] showed that for the diffraction from the last rooftop to street in COST 231-WI model was found to be erroneous. Correspondingly, COST 231WI predicts a path loss of $8.7 \mathrm{~dB}$ more optimistic than it is supposed to be. The authors have showed that by comparing with Felsen's diffraction model the term -16.9 should be replaced by -8.2 . Here $L_{\mathrm{rts}}$ according to Har is given by

$$
L_{\mathrm{rts}}=-8.2-10 \log w+10 \log f+20 \log \Delta h+L_{\mathrm{ori}}
$$

The total path loss thus obtained with $L_{\mathrm{rts}}$ computed from the modified Ikegami is $4.82 \mathrm{~dB}$ lesser compared with those obtained from Xia's model. In Figure 5, the observed path losses from Kurla base station are compared with those deduced from the above stated approach (here after called modified Xia's model). This gave better agreement with observed values than Xia's original model. These are computed for $h_{\mathrm{b}}$ (base station antenna height) $=15 \mathrm{~m}$ and $d$ (street width) $=50 \mathrm{~m}$ and $x$ (horizontal distance from mobile to last building) $=50 \mathrm{~m}$. The figure depicts that towards the Kalyan side the deviation is slightly higher. At $2 \mathrm{~km}$ distance, the deviation is $5 \mathrm{~dB}$ and good agreement is seen at $6 \mathrm{~km}$. On the other side of the base station, agreement is good between 2 and $3 \mathrm{~km}$ distance and between 7 and $8 \mathrm{~km}$. The sharp rise of the observed path loss between 2 and $3 \mathrm{~km}$ could be due to the fact that train is taking a turn. On the other side of

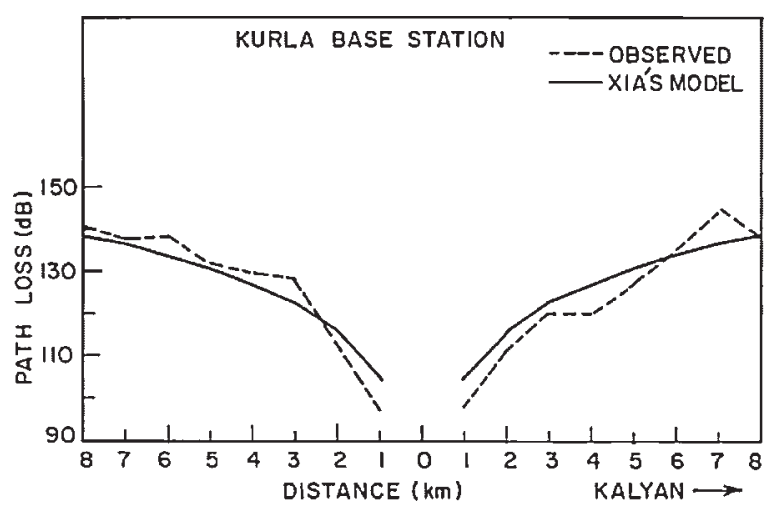

Fig. 5. Comparison of modified Xia's model with the observed path losses of Kurla base station. the base station, the deviations at 2, 4, 6 and $8 \mathrm{~km}$ are $4,3,4$ and $2 \mathrm{~dB}$ respectively.

Figure 6 depicts the comparison of observed path losses deduced from the Delhi base station with those of the modified Xia's model. The model gave reasonable agreement thought about the range of distance. From $6 \mathrm{~km}$ onwards suburban conditions prevailed and Xia's model for suburban conditions has been used. The deviation is slightly higher near $1 \mathrm{~km}$ distance and thereafter it gave good agreement. Most of the time, the deviations are confined to $3-4 \mathrm{~dB}$. The computation of path loss has been done for $h_{\mathrm{b}}=30 \mathrm{~m}$ up to $3 \mathrm{~km}$ and $h_{\mathrm{b}}=15 \mathrm{~m}$ after $3 \mathrm{~km}$ distance. The observed path loss increases up to $6 \mathrm{~km}$ rapidly by $26 \mathrm{~dB}$. From the New Delhi base station up to a distance of $6 \mathrm{~km}$, multi storey buildings, densely populated areas are seen along the track. The large values of path loss could be due to multiple reflections, multiple diffractions of the signal from the buildings. A value of $50 \mathrm{~m}$ has been used for street widths.

\subsubsection{Transportability of study to other environments and frequencies in Indian railways}

The present study can be utilized for the design of future mobile communication systems in other metropolitan cities having more or less similar urban structure. Railway environment in first few hundred meters or 1 kilometer is more or less same in metropolitan cities. The results of these comparisons can be applied to railway environments having more or less similar building structure, degree of urbanization etc.

In the UHF band, the wavelength is less than $1 \mathrm{~m}$ and hence is small compared to building dimensions. So propagation phenomena like diffraction, reflection etc. would be the same. Here the experimental

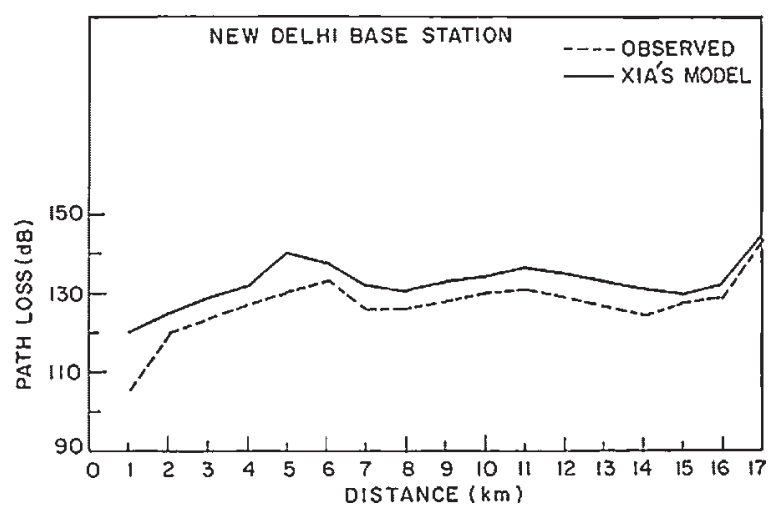

Fig. 6. Comparison of modified Xia's model with the observed path losses of New Delhi base station.

Wirel. Commun. Mob. Comput. 2006; 6:105-112 
observations using the $320 \mathrm{MHz}$ have been utilized to verify the accuracy of prediction methods and study the relative propagation impairments in the UHF band. Propagation phenomena that contribute to path loss like diffraction, reflection, scattering from buildings etc. would also contribute to path loss at higher frequencies like $900 \mathrm{MHz}$ etc. in the UHF band. These models that are found to be accurate from this study can be utilized to predict the path losses at higher frequencies in the UHF band.

\section{Conclusions}

The comparison of the measurements and results of prediction methods showed that in the case of the New Delhi base station Hata's method gave agreement at closer distances below $6 \mathrm{~km}$ with very small deviations, which varied from 3 to $8 \mathrm{~dB}$. In the case of Kurla base station, the agreement is not good at closer distances and it is better beyond $4 \mathrm{~km}$. The deviation varied from 1 to $15 \mathrm{~dB}$. The agreement of UTD in the case of Kurla base station is better than that of New Delhi base station. The deviation varied between 1 and $6 \mathrm{~dB}$ in the case of Kurla base station whereas in the case of New Delhi base station it varied from 1 to $5 \mathrm{~dB}$. Egli's method deviated appreciably in the case of New Delhi base station and gave good agreement at small distances of less than $3 \mathrm{~km}$ in the case of Kurla base station. In both the cases Blomquist and Ladell's method deviated considerably.

In the case of Kurla base station the observed path losses on both sides of the base station are $108,110 \mathrm{~dB}$ at $2 \mathrm{~km}, 120,132 \mathrm{~dB}$ at $4 \mathrm{~km}$ and $138,138 \mathrm{~dB}$ at $6 \mathrm{~km}$ distances. The corresponding path losses in the case of New Delhi base station are 120, 128 and $135 \mathrm{~dB}$. Here the path loss was reported only on one side of the base station. In the case of both the base stations, at distances of the order of $6 \mathrm{~km}$ or beyond, the path loss is more or less same but at small distances there is a difference in path loss. The major conclusion of this study is that even in the case of widely varying urban environment variations in path loss are seen at closer distances of the order of $5 \mathrm{~km}$ or so. Beyond that variation is smooth. The highlight of this study is the modification of Xia's model using modified Ikegami's model following Har's approach. This approach gave better agreement than the traditional Hata's method in the case of Kurla's base station than New Delhi's base station. This shows that modified Xia's model gives more realistic values in dense high rising environments than Hata's method.

\section{References}

1. Lace LJ, Ramos LR, Cardona N. Application of some theoretical models for coverage prediction in macro cell urban environments. IEEE Transactions on Vehicular Technology 1999; 48(5): 1463-1468.

2. Kukushkin A. Propagation modeling in mobile communications. Australian Telecommunication Research 1994; 28: $1-14$.

3. Chang KR, Kim HT. Prediction of beam tilting effects using an enhanced ray launching model in the urban area. IEEE Transactions on Vehicular Technology 2000; 49(3): 734-743.

4. Goncalves NC, Correia LM. Propagation model for urban micro-cellular systems at the UHF band. In Proceedings of PIMRC 98-IEEE 9th International Symposium on Personal Indoor and Mobile Radio Communications, MA, U.S.A., September 1998.

5. McGuire M, Plataniotis KN, Venetsanopoulos AN. Estimating the position of mobile terminals from path loss measurements with survey data. Wireless Communications and Mobile Computing 2003; 3: 51-62.

6. Hata M. Empirical formula for propagation loss in land mobile radio services. IEEE Transactions on Vehicular Technology 1980; VT-29: 317-325.

7. Blomquist A, Ladell L. Predictions and calculations of transmission loss in different of terrain. NATO AGARD Conf.Pub.Cp 144 Res.Inst.Nat.Defence, Dept.3, 5-10450, 1974, pp 32/1-32/17, Stockholm 80, Sweden.

8. Walfisch J, Bertoni HL. A theoretical model of UHF propagation in urban environments. IEEE Transactions on Antennas and Propagation 1988; 36: 1788-1796.

9. Egli JJ. Radio propagation above $40 \mathrm{Mc}$ over irregular terrain. Proceedings IRE 1957; 45: 1383-1391.

10. Ibrahim MF, Parsons JD. Signal strength prediction in built-up areas. IEE Proceedings 1983; 130(Part F): 377-384.

11. Zhang W. A wide-band propagation model based on UTD for cellular mobile radio communications. IEEE Transactions on Antennas and Propagation 1997; 45(11): 1669-1678.

12. Xia HH. A simplified analytical model for predicting path loss in urban and suburban environments. IEEE Transactions on Vehicular Technology 1997; 46(11): 1040-1046.

13. Xia HH, Bertoni HL. Diffraction of cylindrical and plane waves by an array of absorbing half screens. IEEE Transactions on Antennas and Propagation 1992; 40(2): 170-177.

14. Ikegami F, Yoshida S, Takeuchi T, Umehira M. Propagation factors controlling mean field Strength on urban streets. IEEE Transactions on Antennas and Propagation 1984; 32(8): 822829.

15. Har D, Watson AM, Chadney AG. Comment on diffraction loss of rooftop-to-street in COST231- Walfisch-Ikegami model. IEEE Transactions on Vehicular Technology 1999; 48(5): $1451-1452$.

\section{Authors' Biographies}

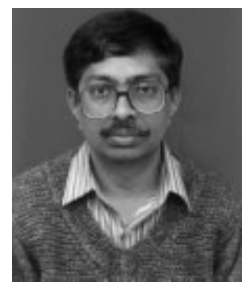

Dr. M. V. S. N. Prasad was born on 10th April 1956 and is presently working as a scientist in Radio Science Division of National Physical Laboratory. His research areas are mobile radio, microwave propagation and satellite communications. He has developed active links with various user organizations in the area of telecommunications 
like VSNL, Railways, DOT, three wings of defense and rendered consultancy services in these areas and established collaborations with many universities. He received the URSI young scientist award in 1990, Best paper award from National Space Science Symposium in 1990, Best paper award from BES (India) in 1998 and was elected as a member of the American Geophysical Union under the Lloyd V. Berkner Fund. He participated in telecommunication and radio wave propagation workshops for the International Center for Theoretical Physics, Trieste, Italy. He has published several papers in national and international journals.

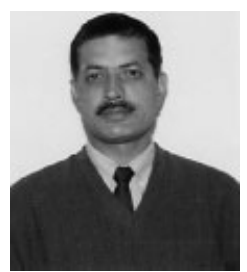

Rajendra Singh was born on 1st March 1958. He received the bachelor of technology degree in electronics and communication engineering from University of Roorkee, India, in 1980, the master of technology degree in communication and radar engineering from Indian Institute of Technology, New Delhi, India in 1991 and the master of business administration degree from the University of Delhi, Delhi, India in 1996. During the last 17 years, he has worked in telecommunication network planning its implementation and maintenance in Indian Railways. He is responsible for the successful installation and commissioning of $18 \mathrm{GHz} 4-$ psk digital radio in the eastern part of India. For 5 years he was associated with a German consultancy firm for finalizing future telecom networks in Indian railways, which included digital microwave, TDMA, digital UHF and satellite locations. Presently, he is an advisor, Telecom Regulatory Authority of India, New Delhi.
Dr. S. K. Sarkar obtained his Ph.D. from the University of Delhi in 1979. Since 1980, he is working as a scientist in the National Physical Laboratory, New Delhi. He has contributed substantially in the area of radioclimatology in relation to tropospheric radio wave propagation both in clear air and precipitation conditions over the Indian subcontinent. He has worked and handled several projects sponsored by DRDO, DOE and DST in the field of radio meteorology and microwave communication. Currently he is engaged in rain related studies as a principal investigator of a DST sponsored project. He has published several papers in the national and international journals.

Prof. A. D. Sarma was born in 1953. He received his M.Sc. (Tech) degree in applied physics from Andhra University in 1977 and Ph.D. in electronic and electrical engineering from London University in 1986. Between 1977 and 1982, he was associated with DEAL (Dehradun), electrical engineering department of IIT, New Delhi and DLRL, Hyderabad. Between 1986 and 1991 he was associated with the Telecommunications Division of Electrical Engineering department of Eindhoven University of Technology, The Netherlands and Wave Propagation Laboratory of NOAA, Boulder (U.S.A.). Presently, he is working as a scientist/ professor at Research and Training Unit of Navigational Electronics, Osmania University, Hyderabad. He has several publications to his credit both in national and international journals. His interests include radio wave propagation, microwave and millimeter wave systems, high frequency antenna analysis and GPS. He is a member of IETE, IGU and AGU (U.S.A.). 